\title{
Usefulness of Standardized Uptake Values for Distinguishing Adrenal Glands with Pheochromocytoma from Normal Adrenal Glands by Use of $6-{ }^{18}$ F-Fluorodopamine PET
}

Henri J.L.M. Timmers ${ }^{1,2}$, Jorge A. Carrasquillo ${ }^{3}$, Millie Whatley ${ }^{3}$, Graeme Eisenhofer ${ }^{4}$, Clara C. Chen ${ }^{3}$, Alexander Ling ${ }^{5}$, W. Marston Linehan ${ }^{6}$, Peter A. Pinto ${ }^{6}$, Karen T. Adams ${ }^{1}$, and Karel Pacak ${ }^{1}$

${ }^{1}$ Reproductive and Adult Endocrinology Program, National Institute of Child Health and Human Development, National Institutes of Health, Bethesda, Maryland; ${ }^{2}$ Department of Endocrinology, Radboud University Nijmegen Medical Centre, Nijmegen, The Netherlands; ${ }^{3}$ Department of Nuclear Medicine, Warren G. Magnuson Clinical Center, National Institutes of Health, Bethesda, Maryland; ${ }^{4}$ Clinical Neurocardiology Section, National Institute of Neurological Disorders and Stroke, National Institutes of Health, Bethesda, Maryland; ${ }^{5}$ Department of Diagnostic Radiology, Warren G. Magnuson Clinical Center, National Institutes of Health, Bethesda, Maryland; and ${ }^{6}$ Urologic Oncology Branch, Center for Cancer Research, National Cancer Institute, National Institutes of Health, Bethesda, Maryland

\begin{abstract}
6-18 F-Fluorodopamine ( $\left.{ }^{18} \mathrm{~F}-\mathrm{FDA}\right) \mathrm{PET}$ is a highly sensitive tool for the localization of pheochromocytoma (PHEO). The aim of this study was to establish cutoff values for pathologic and physiologic adrenal gland tracer uptake. Methods: ${ }^{18} \mathrm{~F}-\mathrm{FDA}$ PET with CT coregistration was performed in 14 patients (10 men and 4 women; age [mean $\pm \mathrm{SD}$ ], $42.9 \pm 13.3 \mathrm{y}$ ) with unilateral adrenal gland PHEO and in 13 control subjects ( 5 men and 8 women; age, $51.7 \pm 12.5 \mathrm{y}$ ) without PHEO. Standardized uptake values (SUVs) were compared between adrenal glands with PHEO and normal left adrenal glands in control subjects. Results: ${ }^{18} \mathrm{~F}-\mathrm{FDA}$ accumulation was observed in all adrenal glands with PHEO and in 6 of 13 control adrenal glands $(P=0.02)$. The SUV was higher in adrenal glands with PHEO (mean \pm SD, $16.1 \pm 6.1$ ) than in ${ }^{18}$ F-FDA-positive control adrenal glands $(7.7 \pm 1.4)(P=$ 0.005). SUV cutoffs for distinguishing between adrenal glands with PHEO and normal adrenal glands were 7.3 (100\% sensitivity) and 10.1 (100\% specificity). Conclusion: The SUVs of adrenal foci on ${ }^{18} \mathrm{~F}-\mathrm{FDA}$ PET facilitate the distinction between adrenal glands with PHEO and normal adrenal glands.
\end{abstract}

Key Words: 6-18F-fluorodopamine; pheochromocytoma; paraganglioma; PET

J Nucl Med 2007; 48:1940-1944

DOI: 10.2967/jnumed.107.043281

$\mathbf{P}$ (PHEOs) are rare catecholamineproducing tumors of the adrenal medulla $(1,2)$. The

Received May 2, 2007; revision accepted Aug. 24, 2007.

For correspondence contact: Karel Pacak, M.D, Ph.D., D.Sc., Reproductive and Adult Endocrinology Program, National Institute of Child Health and Human Development, 10 Center Dr., Bldg. 10, CRC, Room 1-E 3140, MSC 1109, Bethesda, MD 20892-1109.

E-mail: karel@mail.nih.gov

COPYRIGHT @ 2007 by the Society of Nuclear Medicine, Inc. diagnosis of PHEO can be reliably confirmed or excluded by the biochemical parameter of catecholamine excess, in particular, fractionated metanephrines in urine or plasma (3). The localization of PHEO usually requires both anatomic and functional imaging studies. Agents that specifically target the catecholamine storage and secretion pathways include ${ }^{123} \mathrm{I} /{ }^{131} \mathrm{I}$-metaiodobenzylguanidine and $6-{ }^{18} \mathrm{~F}$-fluorodopamine $\left({ }^{18} \mathrm{~F}-\mathrm{FDA}\right)(4,5)$. In our experience, ${ }^{18} \mathrm{~F}$-FDA PET is a highly sensitive tool for localizing PHEO $(4,6)$ but may lead to falsepositive results because of physiologic uptake by normal adrenal glands. This uptake can be particularly misleading in patients who are prone to bilateral PHEOs because of underlying genetic abnormalities $(7,8)$.

The aim of this study was to establish cutoff values for pathologic and physiologic adrenal gland tracer uptake for ${ }^{18} \mathrm{~F}-\mathrm{FDA}$ PET. For this purpose, the distributions of ${ }^{18} \mathrm{~F}-\mathrm{FDA}$ in adrenal glands and other tissues in patients with benign PHEO and control subjects without PHEO were compared.

\section{MATERIALS AND METHODS}

\section{Patients}

A total of 104 consecutive patients were referred for known or suspected PHEO and underwent ${ }^{18} \mathrm{~F}-\mathrm{FDA}$ PET/CT between March 2005 and June 2006. After exclusion of patients with extraadrenal or metastatic PHEO, 14 patients (10 men and 4 women; age [mean $\pm \mathrm{SD}$ ], $42.9 \pm 13.3$ y) with histologically confirmed adrenal gland PHEO were studied. Underlying genotypes are indicated in Table 1 . The control group consisted of 13 subjects ( 5 men and 8 women; age, $51.7 \pm 12.5$ y). Reasons for PHEO evaluation are indicated in Table 1 . In all control subjects, PHEO was ruled out by normal plasma free metanephrine levels and clinical follow-up (3). The study protocol was approved by the Institutional Review Board of the National Institutes of Child 
Health and Development, National Institutes of Health. All patients provided written informed consent.

\section{${ }^{18}$ F-FDA PET}

${ }^{18}$ F-FDA PET was performed as previously described (9) with a Discovery ST PET/CT scanner (GE Healthcare). The injected ${ }^{18} \mathrm{~F}-$ FDA dose was typically $37 \mathrm{MBq}$, that is, a mean mass of 400 (range, $180-810) \mu g$ of ${ }^{18}$ F-FDA with a mean specific activity of 38 (range, about 30-49) GBq/mmol.

\section{Analysis of Data}

${ }^{18}$ F-FDA PET/CT studies were read by a nuclear medicine physician who was unaware of the results of other investigations. Any visible adrenal foci of uptake higher than the background were considered ${ }^{18} \mathrm{~F}$-FDA positive. Standardized uptake values (SUVs) corrected for lean body mass were calculated (SUV = $[\mathrm{Bq} / \mathrm{g}$ per $\mathrm{Bq}$ injected] $\times$ lean body mass) with software from MedImage. Maximum SUVs were determined in manually drawn regions of interest over adrenal lesions and in normal left adrenal glands, as delineated by CT. The SUV was not calculated for ${ }^{18} \mathrm{~F}$ FDA-negative right adrenal glands to exclude interference from physiologic uptake by the liver and the biliary tract. Left adrenal gland SUVs of control subjects served as a reference for normal uptake.

Regions of interest were also drawn manually around the parotid gland, the thyroid gland, and the myocardium and in 4 consecutive slices around the right lung (level below the carina), the liver (upper part), the spleen (middle part), and the pancreas (body), as delineated by CT. Under the assumption of a homogeneous tracer distribution in the large organs, average SUVs were calculated for the central parts of the lungs, liver, and spleen. For the smaller organs, maximum SUVs were used, because estimates of average SUVs in smaller structures may be hampered by resolution limitations.

\section{Statistics}

Results are reported as mean \pm SD. Fisher exact and unpaired Student $t$ tests were used for comparisons of the numbers of ${ }^{18} \mathrm{~F}$ FDA-positive adrenal glands and SUVs, respectively. A 2-sided $P$ value of $<0.05$ was considered significant. A receiver operating characteristic (ROC) curve was constructed for different upper reference limits of SUVs (10). Statistical analysis was performed

TABLE 1

Adrenal Imaging Results

\begin{tabular}{|c|c|c|c|c|c|c|}
\hline \multirow[b]{3}{*}{$\begin{array}{l}\text { Patient }(\mathrm{P}) \text { or } \\
\text { control subject }(\mathrm{C})\end{array}$} & \multirow[b]{3}{*}{$\begin{array}{l}\text { Sex, } \\
\text { age (y) }\end{array}$} & \multirow[b]{3}{*}{ Syndrome* } & \multirow[b]{3}{*}{ Reason for evaluation } & \multicolumn{3}{|l|}{ Results of: } \\
\hline & & & & \multirow[b]{2}{*}{ CT or MRI of adrenal glands } & \multicolumn{2}{|c|}{${ }^{18} \mathrm{~F}-\mathrm{FDA}$ PET } \\
\hline & & & & & $\begin{array}{l}\text { Gland } \\
\text { status }^{\dagger}\end{array}$ & SUV $\ddagger$ \\
\hline $\mathrm{P} 1$ & M, 62 & VHL & & L PHEO, $3.0 \mathrm{~cm}$; R nodule & POS & 7.3 \\
\hline $\mathrm{P} 2$ & M, 31 & MEN2a & & R PHEO, $3.4 \mathrm{~cm}$; L normal & POS & 8.5 \\
\hline P3 & M, 35 & Pending & & R PHEO, $2.0 \mathrm{~cm}$; L normal & POS & 10.4 \\
\hline P4 & $F, 52$ & VHL & & L PHEO, $1.0 \mathrm{~cm}$; R adrenalectomy & POS & 10.8 \\
\hline P5 & $\mathrm{F}, 42$ & VHL & & R PHEO, $1.4 \mathrm{~cm}$; L adrenalectomy & POS & 11.5 \\
\hline P6 & $M, 47$ & VHL & & L PHEO, $2.5 \mathrm{~cm} ; \mathrm{R}$ nodule & POS & 12.0 \\
\hline $\mathrm{P} 7$ & $M, 50$ & VHL & & L PHEO, $2.2 \mathrm{~cm}$; R adrenalectomy & POS & 12.6 \\
\hline P8 & $\mathrm{M}, 30$ & VHL & & L PHEO, $2.5 \mathrm{~cm}$; R adrenalectomy & POS & 17.6 \\
\hline P9 & M, 28 & Pending & & R PHEO, $3.5 \mathrm{~cm}$; L normal & POS & 19.8 \\
\hline P10 & $\mathrm{F}, 55$ & Sporadic & & L PHEO, 2.4 cm; R normal & POS & 20.1 \\
\hline $\mathrm{P} 11$ & M, 23 & VHL & & L PHEO, $1.6 \mathrm{~cm}$; R normal & POS & 21.1 \\
\hline $\mathrm{P} 12$ & $M, 58$ & Sporadic & & R PHEO, $3.5 \mathrm{~cm}$; L normal & POS & 22.3 \\
\hline $\mathrm{P} 13$ & $F, 26$ & SDHD & & R PHEO, 1.8; L adrenalectomy & POS & 24.8 \\
\hline $\mathrm{P} 14$ & $M, 61$ & SDHD & & R PHEO, $2.0 \mathrm{~cm}$; L normal & POS & 26.3 \\
\hline $\mathrm{C} 1$ & $F, 69$ & & Family history of PHEO & L normal; R normal & NEG & 3.8 \\
\hline $\mathrm{C} 2$ & $F, 49$ & & Symptoms & L normal; R normal & NEG & 3.9 \\
\hline $\mathrm{C} 3$ & $M, 17$ & & Hypertension & L normal; R normal & NEG & 4.7 \\
\hline $\mathrm{C} 4$ & $F, 55$ & & Hypertension and symptoms & L normal; R normal & NEG & 5.1 \\
\hline C5 & $F, 56$ & & Hypertension and symptoms & L normal; R normal & POS & 5.7 \\
\hline C6 & $M, 44$ & VHL & $\begin{array}{l}\text { Screening for PHEO because } \\
\text { of known VHL }\end{array}$ & L normal; R normal & NEG & 5.8 \\
\hline $\mathrm{C} 7$ & $F, 63$ & & Incidentaloma & $L$ nodule, $2.1 \mathrm{~cm}$; R normal & POS & 6.2 \\
\hline $\mathrm{C} 8$ & $\mathrm{~F}, 44$ & & Hypertension and symptoms & L normal; R normal & NEG & 6.4 \\
\hline C9 & $M, 60$ & & Hypertension and symptoms & L normal; R normal & POS & 7.2 \\
\hline C10 & $F, 48$ & & Hypertension & L normal; R normal & POS & 8.3 \\
\hline $\mathrm{C} 11$ & $M, 51$ & & Incidentaloma & L nodule, $11 \mathrm{~cm}$; R normal & POS & 9.2 \\
\hline $\mathrm{C} 12$ & M, 52 & & Hypertension and symptoms & L normal; R normal & POS & 9.5 \\
\hline $\mathrm{C} 13$ & $F, 65$ & & Incidentaloma & $L$ nodule, $3 \mathrm{~cm}$; $R$ nodule, $2 \mathrm{~cm}$ & NEG & 9.8 \\
\hline
\end{tabular}

${ }^{\star} \mathrm{VHL}=$ von Hippel-Lindau disease; MEN2a = multiple endocrine neoplasia (type lla); pending = genetic testing incomplete; sporadic = syndrome excluded; SDHD = succinate dehydrogenase subunit $\mathrm{D}$.

${ }^{\dagger}$ Gland status: POS = positive for PHEO; NEG = negative for PHEO. Data for control subjects are for left adrenal glands.

${ }^{\ddagger}$ Maximum SUV corrected for lean body mass. 
with the Statistical Package for the Social Sciences (SPSS for Windows 12; SPSS Inc.).

\section{RESULTS}

\section{Uptake of ${ }^{18}$ F-FDA by Adrenal Glands with PHEO Versus} Normal Adrenal Glands

CT or MRI showed an adrenal tumor in all patients with PHEO. All 14 tumors were ${ }^{18} \mathrm{~F}$-FDA positive (Table 1 and Fig. 1). Six of 13 control left adrenal glands (46\%) were ${ }^{18}$ F-FDA positive; 2 of these contained an incidentaloma ( $P=0.02$ for controls vs. adrenal glands with PHEO) (Table 1). Maximum SUVs were higher in adrenal glands with PHEO (16.1 \pm 6.1 ; range, $7.3-26.3)$ than in ${ }^{18}$ F-FDApositive control left adrenal glands (7.7 \pm 1.4 ; range, 5.7-9.5) $(P=0.005)$ (Fig. 2). The mean SUV in all control left adrenal glands, that is, ${ }^{18} \mathrm{~F}$-FDA positive and negative, was $6.6 \pm$ 2.0 (range, 3.8-9.8) $(P<0.001$ for controls vs. adrenal glands with PHEO).

The area under the ROC curve for adrenal gland SUVs was 0.962 (Fig. 3). To provide 100\% sensitivity, the upper reference for a normal SUV was established at 7.3, resulting in a specificity of $69 \%$. To provide $100 \%$ specificity, the upper reference for normal was established at 10.1 , resulting in a sensitivity of $86 \%$. With this cutoff value, false-negative results were obtained in 2 patients (patients 1 and 2). The diameters of these tumors were $3 \mathrm{~cm}$ (patient 1) and $3.4 \mathrm{~cm}$ (patient 2); the latter was hemorrhagic.

\section{Extraadrenal Tissue Distributions of ${ }^{18} \mathrm{~F}-\mathrm{FDA}$}

Physiologic ${ }^{18} \mathrm{~F}$-FDA uptake was observed in the salivary and thyroid glands, heart, lungs, liver, kidneys, pancreas, and bowel (Table 2 and Fig. 4), and values were similar between patients with PHEO and control subjects (Table 2).

\section{DISCUSSION}

${ }^{18} \mathrm{~F}-\mathrm{FDA}$ PET is a promising tool for the localization of PHEO $(4,11) .{ }^{18} \mathrm{~F}$-FDA is actively transported into neurosecretory granules of catecholamine-producing cells via vesicular monoamine transporters after uptake into cells by the norepinephrine transporter $(12,13)$. We previously observed excellent sensitivity of ${ }^{18}$ F-FDA PET for the localization of benign PHEO (4). However, physiologic ${ }^{18}$ F-FDA uptake by normal adrenal glands and extraadrenal tissues is a possible confounder in the identification of adrenal gland PHEO and extraadrenal paraganglioma or metastases, respectively. In the present study, almost half of the control subjects had ${ }^{18} \mathrm{~F}$ FDA-positive results. In our previous study, only 2 of 11 PHEO-negative subjects had false-positive ${ }^{18} \mathrm{~F}-\mathrm{FDA}$ PET results. However, systematic investigation of the adrenal glands in our previous study and other early ${ }^{18}$ F-FDA PET studies $(6,14)$ was hampered by the lack of coregistered CT. Physiologic uptake is probably even higher when higher tracer doses are administered. In a pilot study (data not shown), we performed non-CT-coregistered ${ }^{18} \mathrm{~F}$-FDA PET with a dose of $148 \mathrm{MBq}$ instead of $37 \mathrm{MBq}$ in 7 control
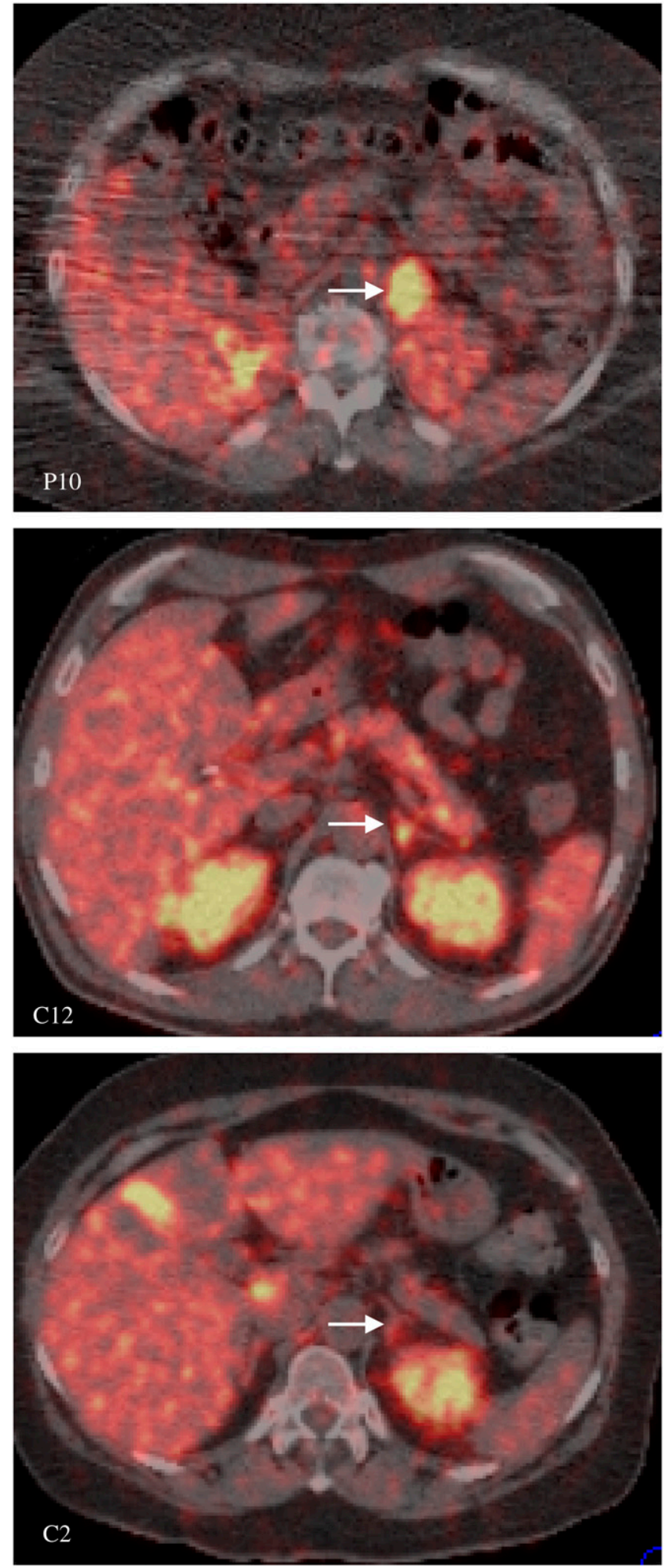

FIGURE 1. Cross-sectional 18F-FDA PET/CT images of patient with left adrenal gland PHEO (P10: ${ }^{18} \mathrm{~F}-\mathrm{FDA}$ positive, SUV $=20.1)$ and 2 control subjects with normal left adrenal glands (C12: ${ }^{18} \mathrm{~F}-\mathrm{FDA}$ positive, SUV = 9.5; C2: ${ }^{18} \mathrm{~F}-\mathrm{FDA}$ negative, SUV $=3.9$ ). Arrows indicate left adrenal gland areas. 


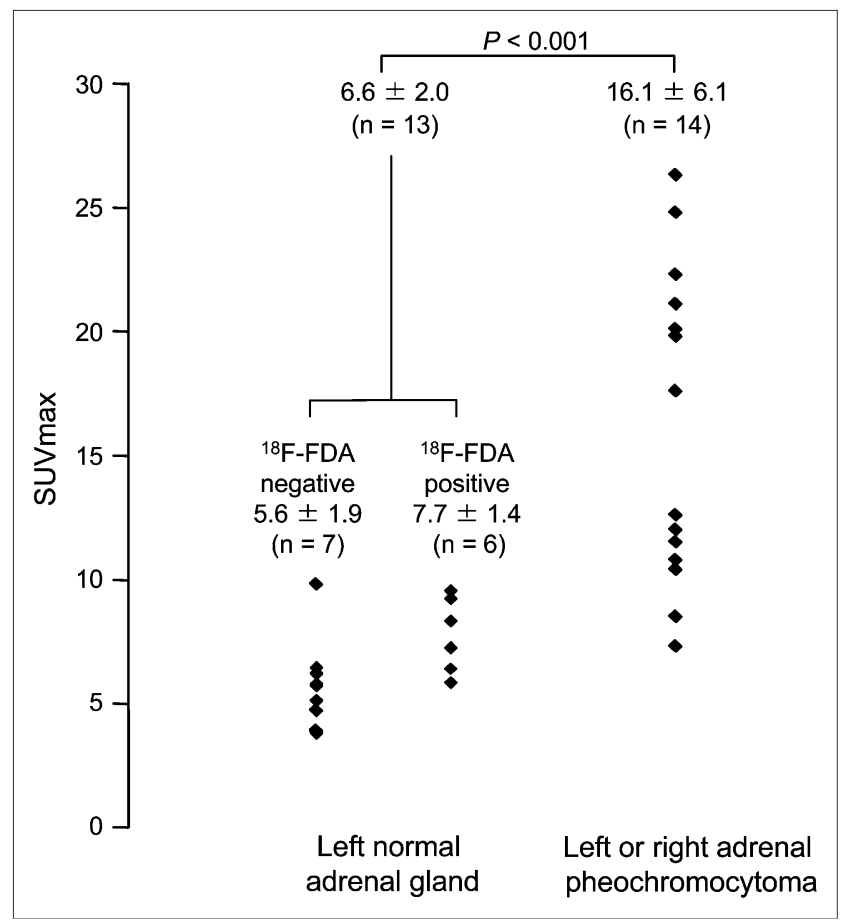

FIGURE 2. ${ }^{18} \mathrm{~F}-\mathrm{FDA}$ PET SUVs in normal left adrenal glands and left or right adrenal glands with PHEO. SUVmax = maximum SUV.

subjects without PHEO. With this higher dose, all normal left adrenal glands except for one were ${ }^{18} \mathrm{~F}-\mathrm{FDA}$ positive, with a mean SUV of $8.8 \pm 3.2$.

We have found that SUVs of adrenal foci on ${ }^{18} \mathrm{~F}-\mathrm{FDA}$ PET can help distinguish between PHEO-related uptake and physiologic uptake in the adrenal glands. SUV cutoffs were

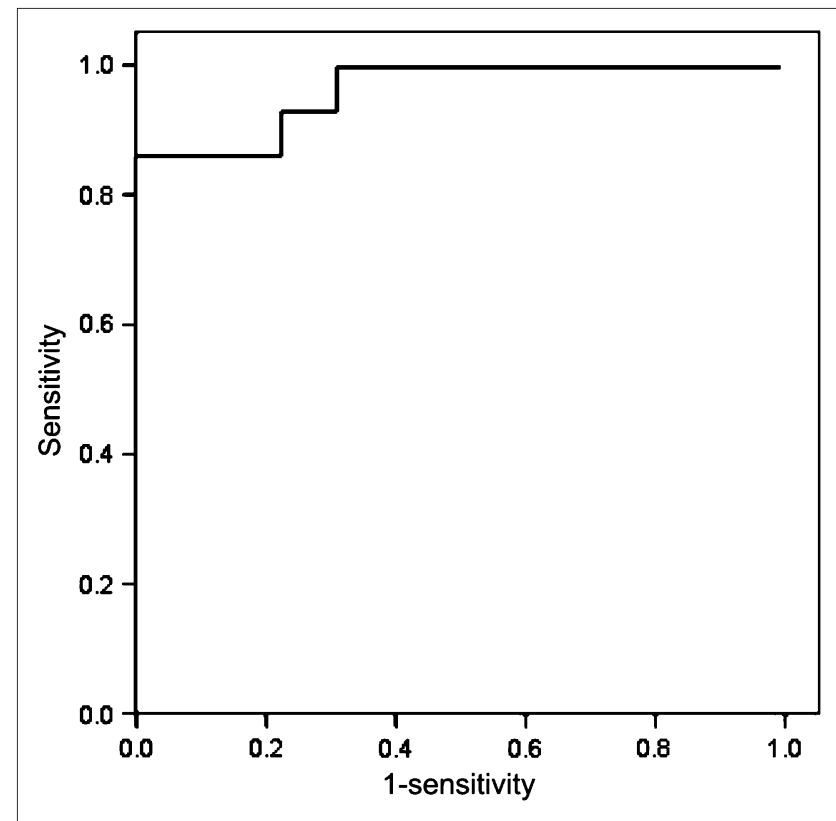

FIGURE 3. ROC curve for ${ }^{18}$ F-FDA PET SUVs.
TABLE 2

Organ Distributions of Physiologic ${ }^{18} \mathrm{~F}-\mathrm{FDA}$ Uptake

\begin{tabular}{llll}
\hline \multirow{3}{*}{ Type of SUV } & \multicolumn{2}{c}{ SUV (mean \pm SD) in: } \\
\cline { 3 - 4 } Mean & \multicolumn{1}{c}{ Organ } & Patients & $\begin{array}{r}\text { Control } \\
\text { subjects }\end{array}$ \\
\hline \multirow{4}{*}{ Maximum } & Liver & $3.0 \pm 0.6$ & $3.1 \pm 0.5$ \\
& Spleen & $2.7 \pm 1.6$ & $2.2 \pm 0.4$ \\
& Lungs & $0.9 \pm 0.3$ & $0.7 \pm 0.1$ \\
& Right parotid gland & $2.7 \pm 0.6$ & $2.8 \pm 1.0$ \\
& Left parotid gland & $2.8 \pm 0.7$ & $2.7 \pm 1.0$ \\
& Thyroid & $3.0 \pm 1.5$ & $3.1 \pm 0.9$ \\
& Myocardium & $7.6 \pm 1.9$ & $7.3 \pm 1.5$ \\
& Pancreas & $7.1 \pm 1.6$ & $6.1 \pm 1.3$ \\
& Left adrenal gland & & $5.4 \pm 1.1$ \\
\hline
\end{tabular}

established at $<7.3$ for physiologic uptake and $>10.1$ for PHEO-related uptake (100\% specificity and $100 \%$ sensitivity, respectively). However, findings on ${ }^{18}$ F-FDA PET should always be interpreted in conjunction with other radiologic, biochemical, and clinical characteristics. In particular, patients with underlying gene mutations predisposing them to recurrent and bilateral PHEOs warrant careful follow-up despite negative PET results. Furthermore, in the diagnostic work-up of PHEO, ${ }^{18}$ F-FDA PET is best positioned as a localizing tool, not as a screening method for the presence of a PHEO. As pointed out earlier, biochemical screening represents the gold standard for confirming or ruling out the diagnosis. Also, with respect to screening for bilateral PHEOs, it is unknown whether adrenal gland uptake of

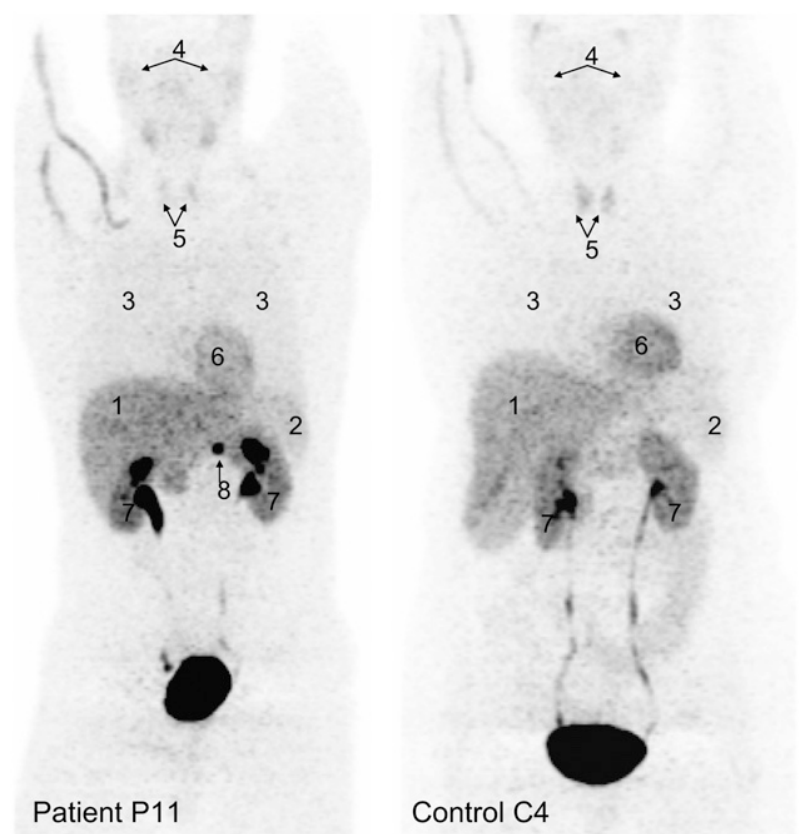

FIGURE 4. Tissue distributions of ${ }^{18} \mathrm{~F}-\mathrm{FDA}$. Anterior reprojected ${ }^{18} \mathrm{~F}-\mathrm{FDA}$ PET images of patient with left adrenal gland PHEO (P11) and control subject (C4). 1 = liver; 2 = spleen; $3=$ lungs; $4=$ parotid glands; $5=$ thyroid gland; $6=$ heart; $7=$ kidneys; $8=$ PHEO. Adrenal glands in control subject were considered ${ }^{18} \mathrm{~F}-\mathrm{FDA}$ negative. 
${ }^{18} \mathrm{~F}$-FDA is altered by previous surgical resection of the contralateral gland. Theoretically, compensatory hypertrophy of the remaining adrenal medulla could lead to enhanced ${ }^{18} \mathrm{~F}$-FDA uptake and false-positive results.

\section{CONCLUSION}

In conclusion, calculation of SUVs of adrenal foci on ${ }^{18}$ F-FDA PET facilitates the distinction between PHEOrelated and physiologic tracer accumulation in the adrenal glands. The diagnosis of PHEO is highly unlikely when the adrenal gland SUV is below 7.3 and very likely when it exceeds 10.1 .

\section{ACKNOWLEDGMENTS}

This research was supported by the Intramural Research Program of the NICHD, NIH, and, in part, by the Intramural Research Program of the Center for Cancer Research, National Cancer Institute, NIH. We thank Jacques Lenders for helpful discussions and feedback on the article.

\section{REFERENCES}

1. Lenders JW, Eisenhofer G, Mannelli M, Pacak K. Phaeochromocytoma. Lancet. 2005;366:665-675.

2. Pacak P, Eisenhofer G. Pheochromocytoma. In: De Groot LJ, Jameson JL, eds. Textbook of Endocrinology. Philadelphia, PA: Elsevier Saunders, Inc.; 2005: 2501-2534.
3. Lenders JW, Pacak K, Walther MM, et al. Biochemical diagnosis of pheochromocytoma: which test is best? JAMA. 2002;287:1427-1434.

4. Pacak K, Eisenhofer G, Carrasquillo JA, Chen CC, Li ST, Goldstein DS. 6$\left[{ }^{18} \mathrm{~F}\right]$ Fluorodopamine positron emission tomographic (PET) scanning for diagnostic localization of pheochromocytoma. Hypertension. 2001;38:6-8.

5. Shulkin BL, Thompson NW, Shapiro B, Francis IR, Sisson JC. Pheochromocytomas: imaging with 2-[fluorine-18]fluoro-2-deoxy-D-glucose PET. Radiology. 1999;212:35-41.

6. Ilias I, Yu J, Carrasquillo JA, et al. Superiority of $6-\left[{ }^{18} \mathrm{~F}\right]$-fluorodopamine positron emission tomography versus $\left[{ }^{131} \mathrm{I}\right]$-metaiodobenzylguanidine scintigraphy in the localization of metastatic pheochromocytoma. J Clin Endocrinol Metab. 2003; 88:4083-4087.

7. Bravo EL, Tagle R. Pheochromocytoma: state-of-the-art and future prospects. Endocrinol Rev. 2003;24:539-553.

8. Kaltsas GA, Papadogias D, Grossman AB. The clinical presentation (symptoms and signs) of sporadic and familial chromaffin cell tumours (phaeochromocytomas and paragangliomas). Front Horm Res. 2004;31:61-75.

9. Timmers HJ, Kozupa A, Chen CC, et al. Superiority of fluorodeoxyglucose positron emission tomography to other functional imaging techniques in the evaluation of metastatic SDHB-associated pheochromocytoma and paraganglioma. J Clin Oncol. 2007;25:2262-2269.

10. Beck JR, Shultz EK. The use of relative operating characteristic (ROC) curves in test performance evaluation. Arch Pathol Lab Med. 1986;110:13-20.

11. Pacak K, Goldstein DS, Doppman JL, Shulkin BL, Udelsman R, Eisenhofer GA. "Pheo" lurks: novel approaches for locating occult pheochromocytoma. J Clin Endocrinol Metab. 2001;86:3641-3646.

12. Eisenhofer $\mathrm{G}$. The role of neuronal and extraneuronal plasma membrane transporters in the inactivation of peripheral catecholamines. Pharmacol Ther. 2001;91: 35-62.

13. Ilias I, Shulkin B, Pacak K. New functional imaging modalities for chromaffin tumors, neuroblastomas and ganglioneuromas. Trends Endocrinol Metab. 2005; 16:66-72.

14. Mamede M, Carrasquillo JA, Chen CC, et al. Discordant localization of $2-\left[{ }^{18} \mathrm{~F}\right]$-fluoro-2-deoxy-D-glucose in $6-\left[{ }^{18} \mathrm{~F}\right]$-fluorodopamine- and $[(123) \mathrm{I}]-$ metaiodobenzylguanidine-negative metastatic pheochromocytoma sites. $\mathrm{Nucl}$ Med Commun. 2006;27:31-36. 